\title{
Laboratory and modeling studies on the effects of water and soot emissions and ambient conditions on the properties of contrail ice particles in the jet regime
}

\author{
H.-W. Wong ${ }^{1}$, A. J. Beyersdorf ${ }^{2}$, C. M. Heath ${ }^{3}$, L. D. Ziemba ${ }^{2}$, E. L. Winstead ${ }^{2}$, K. L. Thornhill ${ }^{2}$, K. M. Tacina ${ }^{3}$, \\ R. C. Ross $^{3}$, S. E. Albo ${ }^{1}$, D. L. Bulzan ${ }^{3}$, B. E. Anderson ${ }^{2}$, and R. C. Miake-Lye ${ }^{1}$ \\ ${ }^{1}$ Center for Aero-Thermodynamics, Aerodyne Research, Inc., Billerica, Massachusetts, USA \\ ${ }^{2}$ Chemistry and Dynamics Branch, Science Directorate, NASA Langley Research Center, Hampton, Virginia, USA \\ ${ }^{3}$ Combustion Branch, NASA Glenn Research Center, Cleveland, Ohio, USA
}

Correspondence to: H.-W. Wong (hwwong @ aerodyne.com)

Received: 29 August 2011 - Published in Atmos. Chem. Phys. Discuss.: 28 September 2011

Revised: 14 February 2012 - Accepted: 8 August 2013 - Published: 11 October 2013

\begin{abstract}
Contrails and contrail-induced cirrus clouds are identified as the most uncertain components in determining aviation impacts on global climate change. Parameters affecting contrail ice particle formation immediately after the engine exit plane $(<5 \mathrm{~s}$ in plume age) may be critical to ice particle properties used in large-scale models predicting contrail radiative forcing. Despite this, detailed understanding of these parametric effects is still limited. In this paper, we present results from recent laboratory and modeling studies conducted to investigate the effects of water and soot emissions and ambient conditions on near-field formation of contrail ice particles and ice particle properties. The Particle Aerosol Laboratory (PAL) at the NASA Glenn Research Center and the Aerodyne microphysical parcel model for contrail ice particle formation were employed. Our studies show that exhaust water concentration has a significant impact on contrail ice particle formation and properties. When soot particles were introduced, ice particle formation was observed only when exhaust water concentration was above a critical level. When no soot or sulfuric acid was introduced, no ice particle formation was observed, suggesting that ice particle formation from homogeneous nucleation followed by homogeneous freezing of liquid water was unfavorable. Soot particles were found to compete for water vapor condensation, and higher soot concentrations emitted into the chamber resulted in smaller ice particles being formed. Chamber conditions corresponding to higher cruising altitudes were found to favor ice particle formation. The micro-
\end{abstract}

physical model captures trends of particle extinction measurements well, but discrepancies between the model and the optical particle counter measurements exist as the model predicts narrower ice particle size distributions and ice particle sizes nearly a factor of two larger than measured. These discrepancies are likely due to particle loss and scatter during the experimental sampling process and the lack of treatment of turbulent mixing in the model. Our combined experimental and modeling work demonstrates that formation of contrail ice particles can be reproduced in the NASA PAL facility, and the parametric understanding of the ice particle properties from the model and experiments can potentially be used in large-scale models to provide better estimates of the impact of aviation contrails on climate change.

\section{Introduction}

As air traffic and the aviation industry continue to grow, the impact of aviation emissions on climate has also gained increased attention (Brasseur and Gupta, 2010). Condensation trails (contrails) behind aircraft engines are the products of water vapor and soot emissions at cruise. Currently, large uncertainty exists in determining the potential impact of contrails and contrail-induced cirrus clouds on global climate change. Consequently, contrails have been identified as the most uncertain components of the aviation impacts on 
climate change with a low level of scientific understanding (Penner et al., 1999; Lee et al., 2009).

The onset of contrail ice particle formation is believed to be within one wingspan behind the engines. Several processes are involved in the formation of contrail ice particles, including hydrophobic soot surface activation, water vapor condensation on soot surfaces, freezing of the liquid water soot coatings, and further water vapor condensation onto frozen ice surfaces (Kärcher et al., 1996, 1998; Kärcher, 1998). The possibility of contrail formation is traditionally described by the Schmidt-Appleman criterion (Schmidt, 1941; Appleman, 1953; Schumann, 1996, 2005), which states that a contrail will form if the exhaust plume reaches or surpasses saturation with respect to liquid water. The Schmidt-Appleman criterion has been confirmed by observations to be reliable in predicting contrail formation (Kärcher et al., 1996; Jensen et al., 1998; Penner et al., 1999; Heymsfield et al., 2010), suggesting that the controlling factor for contrail formation is thermodynamics. On the other hand, several inflight measurement and modeling studies show that some parameters not considered in the Schmidt-Appleman criterion may affect the properties of contrail ice particles. For example, the European SULFUR inflight measurements (Busen and Schumann, 1995; Schumann et al., 1996, 2002) showed that fuel sulfur can activate soot particles to affect number of ice particles formed. Increased fuel sulfur was also found to cause sooner onset of contrail formation and a $25-50 \%$ increase in number particulates. Recent modeling studies (Kärcher and Yu, 2009; Wong and Miake-Lye, 2010) suggested that soot emissions could affect optical depth of initial contrails and ice particle size and number density. These parameters, though not critical for the threshold temperature of contrail formation, may play an important role in determining ice particle properties used in large-scale models to predict contrail radiative forcing and their climate impacts, especially for scenarios reflecting future fleet emissions burning alternative fuels. Detailed understanding of these parametric effects on contrail ice particle properties in the jet regime (i.e., with a plume age $<5 \mathrm{~s}$ ) is still limited. Since in situ measurements of ice particles in aircraft plumes in the jet regime are challenging due to instrument limitations, well-controlled laboratory experiments in concert with modeling studies provide a costeffective way to understand initial formation mechanisms of contrail ice particles.

This paper discusses results from our coupled laboratory and modeling investigation of the effects of water and soot emissions and ambient conditions on the near-field formation of contrail ice particles. The Particle Aerosol Laboratory (PAL) at the NASA Glenn Research Center (Tacina and Heath, 2010) was employed to simulate a broad range of conditions that bracket those found in the exhaust from aircraft engines at cruise altitudes. The Aerodyne microphysical parcel model for contrail ice particle formation (Wong and Miake-Lye, 2010) was used to guide experimental de- sign and analyze experimental results. Experimental setup and procedures, modeling methodologies, and the results obtained from our studies are presented.

\section{Experimental setup and procedures}

\subsection{NASA's Particle Aerosol Laboratory}

The PAL at the NASA Glenn Research Center (Fig. 1) contains a chamber facility designed to study aviation emissions at simulated altitudes up to $40000 \mathrm{ft}$. During operation, the simulated exhaust is injected upwards into the chamber through a heated transition pipe of $2.43 \mathrm{~cm}$ in diameter and $160 \mathrm{~cm}$ in length. The transition pipe terminates at a $1.0 \mathrm{~cm}$ diameter nozzle centered in the bottom and inside the chamber. Upstream of the nozzle exit, an in-line orifice drops the pressure of the exhaust products to near the chamber background pressure. Controlled amounts of soot particles, humidified air, sulfuric acid, and other trace species may be artificially introduced into the heated transition pipe to mimic aircraft exhaust. The heated pipe can also be connected to a laboratory-scale combustor burning liquid fuels to provide actual combustion exhaust to the chamber.

The cylindrical test section of the chamber measures $183 \mathrm{~cm}$ in height and has an inner diameter of $59.7 \mathrm{~cm}$. A cold nitrogen gas source supplies the working background fluid for the chamber, co-flowing with the nozzle exhaust. Relative humidity of the gas supply may be set up to $100 \%$ for operation temperature below $-54.2^{\circ} \mathrm{C}$. Under warmer chamber temperatures, reduced maximum relative humidity levels can be achieved due to facility limitations. A $152 \mathrm{~cm}$ tall by $10.2 \mathrm{~cm}$ wide instrumentation plate is located on one side of the chamber and contains a series of $1 / 4$ in ports through which exhaust and ice particle samples may be extracted. Three double-paned windows, also $152 \mathrm{~cm}$ tall by $10.2 \mathrm{~cm}$ wide, are spaced $90^{\circ}$ apart around the remaining circumference to provide access for optical measurements. The background nitrogen and combustion products exit the chamber through an exhaust duct located on top; the exhaust, in turn, is connected to a high-flow vacuum source to maintain the chamber at pressures simulating upper tropospheric conditions. More details on chamber operation, including background temperature and pressure profiles, can be found in the paper by Tacina and Heath (2010).

\subsection{Sample introduction and instrumentation}

To simulate aircraft exhaust gas at cruise, water vapor and soot particles were artificially introduced into the PAL chamber via a heated transition pipe upstream of the exhaust nozzle. The water vapor was introduced by a nafion-tube humidifier (Perma Pure, Toms River, NJ). Airflow entering the humidifier is split between 250 nafion tubes. On the outside of the tubes, heated water $\left(70^{\circ} \mathrm{C}\right)$ is circulated. The nafion acts as a selective membrane allowing water to pass into the 


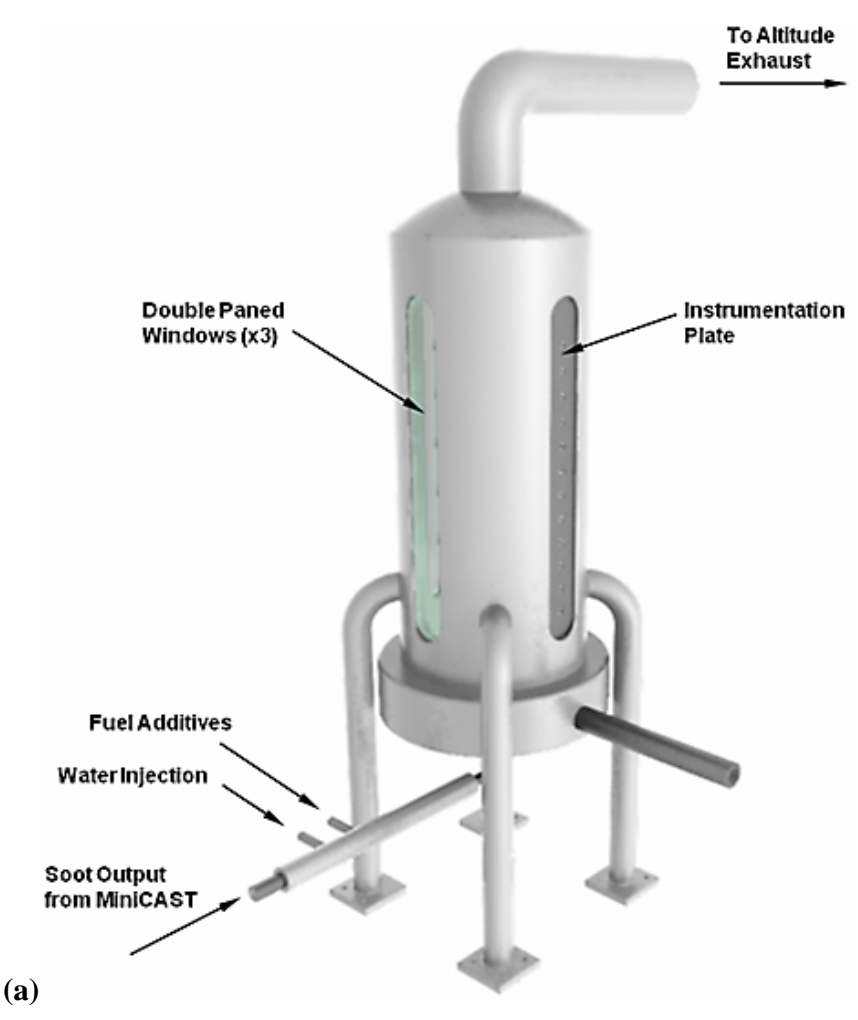

(b)
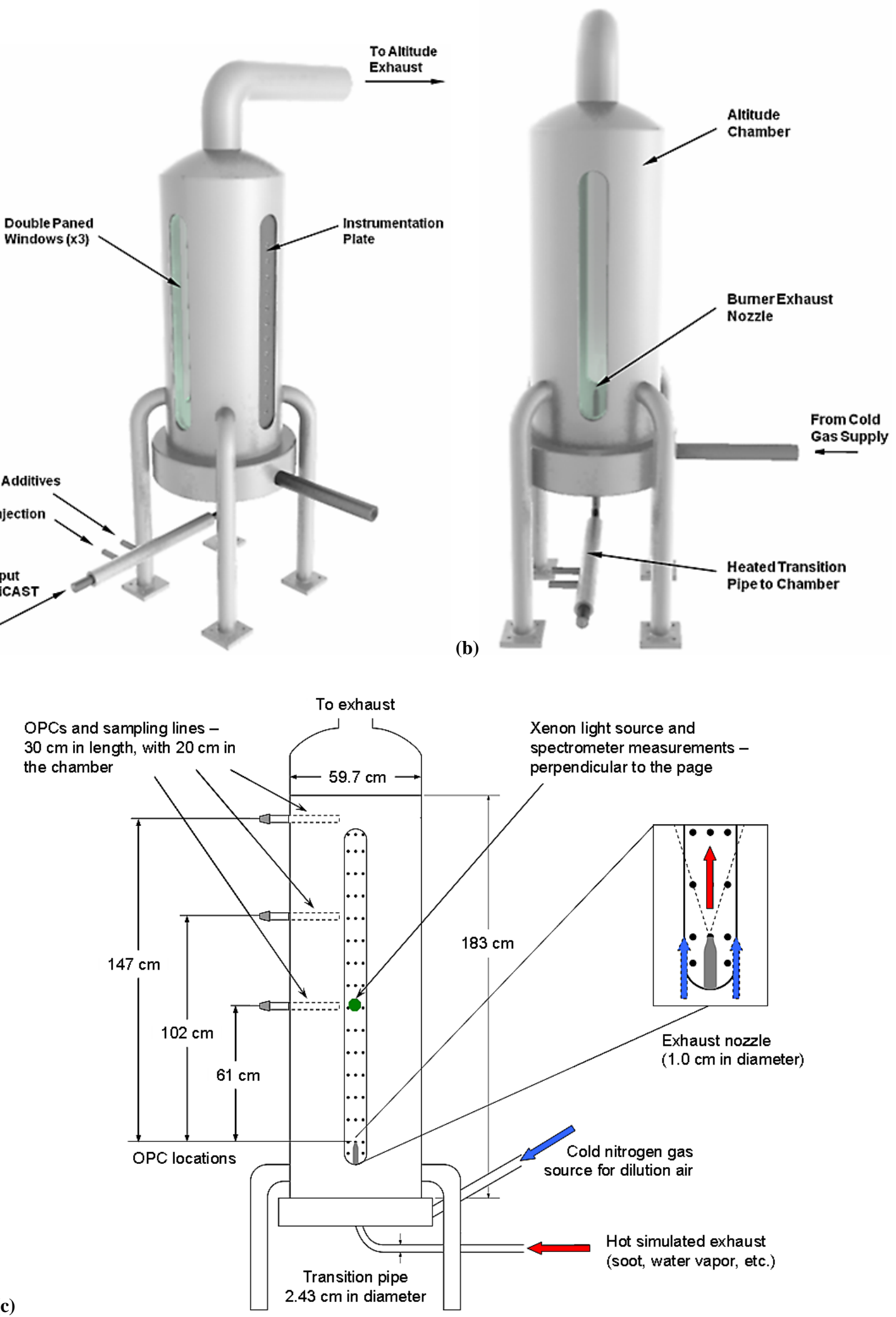

Fig. 1. PAL altitude simulation chamber: (a) isometric view, (b) front view, and (c) schematic representation of the PAL pipes and sampling locations. 
air stream. The water content of the humidified air can be controlled by varying the airflow rate through the humidifier. A Jing Industries mini-Combustion Aerosol Standard 5200 (miniCAST) burner was used to generate combustion soot particles. The miniCAST burns a mixture of propane and air at variable fuel to air ratios to produce a well-characterized, steady-size output of soot particles. During this experiment, the propane-to-air ratio was set at values to give $30-60 \mathrm{~nm}$ diameter soot particles, typical of aircraft exhaust (Timko et al., 2010). In addition to water vapor and soot particles, a known amount of $\mathrm{CO}_{2}$ gas was injected into the transition pipe as a marker for the characterization of exhaust plume dilution in the chamber. To prevent any microphysics from taking place in the transition pipe, the whole transition pipe was heated to $400^{\circ} \mathrm{C}$. The soot particle mass emitted was measured by a multi-angle absorption photometer (MAAP, Petzold et al., 2005) and the particle size distributions by an engine exhaust particle sizer (EEPS, TSI Inc., St. Paul, MN) before injecting into the chamber. The EEPS measured the particle size from 5.6 to $560 \mathrm{~nm}$ at $1 \mathrm{~Hz}$. Particles entering the EEPS are charged with a predictable charge based on particle size. The particles then enter the sizing region which is formed by two concentric cylinders with an electric field between them. Particles are repelled from the inner cylinder to the outer cylinder, which is composed of a series of insulated electrodes. The size of the particles can be derived from the position on the outer cylinder that the charged particles hit (Wang et al., 2006).

To measure ice particle size and number density in the simulated exhaust in the chamber, three horizontal sampling lines with a length of about $30 \mathrm{~cm}$ were installed inside the chamber. The entrances of the sampling lines were located at 61,102 and $147 \mathrm{~cm}$ downstream of the exhaust nozzle and aligned with the chamber centerline. Approximately $20 \mathrm{~cm}$ of these lines were inside the chamber and therefore at the chamber temperature. The remaining $10 \mathrm{~cm}$ were outside the chamber but insulated to reduce sample heating. To characterize exhaust plume dilution, a nondispersive infrared $\mathrm{CO}_{2}$ analyzer (LI-7000, LI-COR BioSciences, Lincoln, NE) was employed to measure $\mathrm{CO}_{2}$ marker concentration at each sampling location and at the exhaust nozzle. One optical particle counter (OPC, Met One Instruments Model 9722, Grants Pass, OR) was connected to each sampling line. In an OPC, airflow is passed through a laser diode beam and the laser light is scattered by the particles in the stream. The scattered light is detected by a photodiode, allowing the particles to be counted, and based on the intensity of the scattered light, the sizes of the particles are determined. The OPCs in our experiments were operated with eight channels that measure ice particle size distributions between 0.3 and $3.0 \mu \mathrm{m}$. However, due to low signals (likely because the OPCs were operated at low chamber pressures), the data was combined into two channels (0.3-1.0 and 1.0-3.0 $\mu \mathrm{m}$, respectively). Sample flow rate through each sampling line was set at 8.8-9.2 standard $\mathrm{mL} \mathrm{min}^{-1}$, which included $0.8-1.2 \mathrm{~mL} \mathrm{~min}^{-1}$ for the
OPC and an $8 \mathrm{~mL} \mathrm{~min}^{-1}$ bypass flow. This flow rate was set to give similar size and concentration response among the OPCs. The high bypass flow rates resulted in very small residence time in the sampling lines, reducing heating in the portion of the sampling lines outside of the chamber and minimizing particle evaporation. Our microphysical calculations also confirmed that ice particle evaporation in the sampling lines is insignificant. Occasionally, ice formation was seen at the inlet tip inside the chamber. This was particularly apparent when operating for a long time at high water concentrations in the exhaust. When this was observed, sampling was stopped and helium was back-flowed through the sample lines until the ice was removed. As a precaution, deicing was also performed periodically throughout the sampling (approximately every $20 \mathrm{~min}$ ).

In addition to the OPCs, a spectrometer system was also employed to measure the optical extinction of ice particles at $61 \mathrm{~cm}$ downstream of the nozzle. A $300 \mathrm{~W}$ xenon light source was coupled through a liquid light guide and collimated to a $25 \mathrm{~mm}$ diameter beam projected through the chamber windows. A BG4 color glass filter was mounted in the optical path of the collimated light to attenuate the green light and raise the short and long wavelength spectrometer measurements, facilitating a more uniform intensity measurement over the spectral range of the spectrometer. The intensity of the light beam was measured using a visible to near infrared (350-1000 nm) spectrometer (Ocean Optics Model USB4000, Dunedin, FL) located in a separate room via $200 \mu \mathrm{m}$ low $\mathrm{OH}$ silica optical fibers with a numerical aperture of 0.22 . The spectral range of the measurements were restricted to $380-850 \mathrm{~nm}$ due to the limitations caused by the xenon light source, collimation optics and window material. Background corrected light intensity measurements before and during each testing were used to calculated light transmittance $(T)$ of the particles in the exhaust plumes. Extinction coefficients of exhaust plumes $(\beta)$ over a distance $(x)$ that the light beam traveled was then calculated using the Beer's law as

$\beta=-\left(\frac{\ln T}{x}\right)$.

The extinction coefficient is equal to the product of ice particle number density $(N)$, particle extinction cross section $(a$, which is proportional to ice particle diameter squared for spherical particles), and extinction efficiency ( $Q_{\text {ext }}$, which varies within a factor of 2 for particles between $0.5-2 \mu \mathrm{m}$ in diameter) as

$\beta=N a Q_{\text {ext }}$.

Assuming $Q_{\text {ext }}$ is constant and ice particles are spherical in our experiments, we can obtain ice particle size and number density information from the extinction coefficient as

$\beta \propto N d^{2}$

where $d$ is the diameter of the ice particles in the exhaust. 


\subsection{Ranges of the parameters examined}

For the sets of experiments presented in this paper, initial water concentration in the exhaust introduced into the chamber was varied between 0 and $5 \%$ in molar fraction. The number density of the polydisperse soot particles introduced by the miniCAST burner ranged between $10^{3}$ and $10^{7}$ particles per $\mathrm{cm}^{3}$. The ranges of water and soot emissions studied in this work were selected to cover typical aircraft emissions at cruise (about $2.5 \%$ molar fraction of water vapor emissions and about $10^{7} \mathrm{~cm}^{-3}$ of soot particles). The exhaust temperature at the nozzle tip was kept constant at $350 \mathrm{~K}$. Four different chamber conditions representing standard day temperature and pressure at cruise altitudes between $25000 \mathrm{ft}$ and $40000 \mathrm{ft}$ were examined. The chamber background temperature and pressure for each of these altitudes are listed in Table 1 . Relative humidity of the chamber co-flow stream was set at $0 \%$. This is because we do not believe it plays a critical role in the initial onset of contrail ice particle formation and $0 \%$ relative humidity in the chamber co-flow stream avoids the possible introduction of undesired ice nuclei that may be contained in the chamber humidification air.

Using the widely used exhaust plume mixing law for a buoyant jet in a co-flowing background fluid (Beer and Chigier, 1972), one can calculate plume temperature and water vapor partial pressure from the tracer measurements as

$\frac{T-T_{\mathrm{b}}}{T_{\mathrm{ex}}-T_{\mathrm{b}}}=\frac{C_{\mathrm{w}}-C_{\mathrm{w}, \mathrm{b}}}{C_{\mathrm{w}, \mathrm{ext}}-C_{\mathrm{w}, \mathrm{b}}}=\frac{C_{\mathrm{t}}-C_{\mathrm{t}, \mathrm{b}}}{C_{\mathrm{t}, \mathrm{ext}}-C_{\mathrm{t}, \mathrm{b}}}$,

where $T, C_{\mathrm{w}}$, and $C_{\mathrm{t}}$ are temperature, concentration of water vapor and concentration of tracer species at the sampling locations. $T_{\mathrm{ex}}, C_{\mathrm{w}, \mathrm{ext}}$, and $C_{\mathrm{t}, \mathrm{ext}}$ are the same properties at the exhaust nozzle tip, and $T_{\mathrm{b}}, C_{\mathrm{w}, \mathrm{b}}$, and $C_{\mathrm{t}, \mathrm{b}}$ are background (chamber) properties. As described earlier, $\mathrm{CO}_{2}$ was used as a tracer species in our measurements. This was done to avoid potential uncertainties to directly measure water vapor concentrations (due to complex water-particle interactions) and plume temperatures (due to turbulent mixing and chamber thermal management). In our experiments, $C_{\mathrm{w}, \mathrm{b}}$ and $C_{\mathrm{t}, \mathrm{b}}$ were set to zero. The exhaust temperature at the nozzle tip $\left(T_{\mathrm{ex}}\right)$ was set at $350 \mathrm{~K}$ and the chamber background temperatures $\left(T_{\mathrm{b}}\right)$ were set to the values listed in Table 1 . This scaling law was found to be robust in laboratory buoyant jets in coflowing fluids, and our previous experimental work showed that it is valid in the PAL chamber (Tacina and Heath, 2010).

Following Eq. (4), one can plot mixing lines of water vapor partial pressure in the plume against plume temperature, alongside liquid water and ice saturation curves, as demonstrated in Fig. 2. Each level of exhaust water corresponds to one of such mixing lines, and according to the SchmidtAppleman criterion, only those mixing lines crossing above the liquid water saturation curve would result in contrail ice particle formation. For example, an exhaust water molar fraction of $0.5 \%$ would not cause contrail formation under the
$35000 \mathrm{ft}$ standard day conditions, as shown in Fig. 2c. Using the formulation given by Schumann (1996), one can calculate a threshold exhaust water molar fraction (the minimum exhaust water molar fraction for contrail formation) for each temperature/pressure combination. Likewise, one can also calculate a threshold temperature (the highest ambient temperature for contrail formation) for each exhaust water level under each temperature/pressure combination. These calculated threshold values are also listed in Table 1.

\section{Modeling methodologies}

In this work, our microphysical parcel model of ice particle formation in the jet regime at cruise (Wong and MiakeLye, 2010) was employed to assist experimental data analysis. Our model tracks time evolution of a gaseous or a particle species in a jet engine exhaust plume in terms of contributions of chemistry, plume dilution and mixing, and microphysical processes as (Kärcher, 1998)

$$
\frac{\mathrm{d} X_{i}}{\mathrm{~d} t}=\left.\frac{\mathrm{d} X_{i}}{\mathrm{~d} t}\right|_{\text {chemistry }}+\left.\frac{\mathrm{d} X_{i}}{\mathrm{~d} t}\right|_{\text {mixing }}+\left.\frac{\mathrm{d} X_{i}}{\mathrm{~d} t}\right|_{\text {microphysics }} .
$$

The contribution of chemistry comes from the chemical molar production rates of gaseous species. In this work, formation of $\mathrm{H}_{2} \mathrm{SO}_{4}$ from $\mathrm{SO}_{3}$ and water (Brown et al., 1996) is the only significant chemical reaction under the conditions of interest.

The contribution of plume dilution and mixing is described as

$$
\left.\frac{\mathrm{d} X_{i}}{\mathrm{~d} t}\right|_{\text {mixing }}=\left(X_{i}-X_{\mathrm{amb}, i}\right) \cdot \frac{\mathrm{d} f(t)}{\mathrm{d} t} \cdot \frac{1}{f(t)},
$$

where $f(t)$ is the exhaust mass fraction, which explains how the exhaust is diluted by the co-flowing air as a function of residence time. In our model, a semi-empirical correlation describing the mixing of an axisymmetric jet in a co-flowing ambient fluid (Nickels and Perry, 1996) was used to evaluate the plume's centerline properties. The calculated exhaust plume's centerline temperature, velocity, and dilution ratio as a function of downstream distance were found to be consistent with experimental data collected in the chamber (Tacina and Heath, 2010).

The contribution of microphysical processes is further divided into contributions of (1) homogeneous nucleation of new liquid particles, (2) coagulation between liquid particles, (3) activation of hydrophobic soot surfaces, (4) condensational growth of water vapor on soot particles, and (5) heterogeneous freezing of liquid coated soot particles:

$$
\begin{aligned}
& \left.\frac{\mathrm{d} X_{i}}{\mathrm{~d} t}\right|_{\text {microphysics }}=\left.\frac{\mathrm{d} X_{i}}{\mathrm{~d} t}\right|_{\text {nucleation }}+\left.\frac{\mathrm{d} X_{i}}{\mathrm{~d} t}\right|_{\text {coagulation }} \\
& +\left.\frac{\mathrm{d} X_{i}}{\mathrm{~d} t}\right|_{\text {activation }}+\left.\frac{\mathrm{d} X_{i}}{\mathrm{~d} t}\right|_{\text {condensation }}+\left.\frac{\mathrm{d} X_{i}}{\mathrm{~d} t}\right|_{\text {freezing }}
\end{aligned}
$$



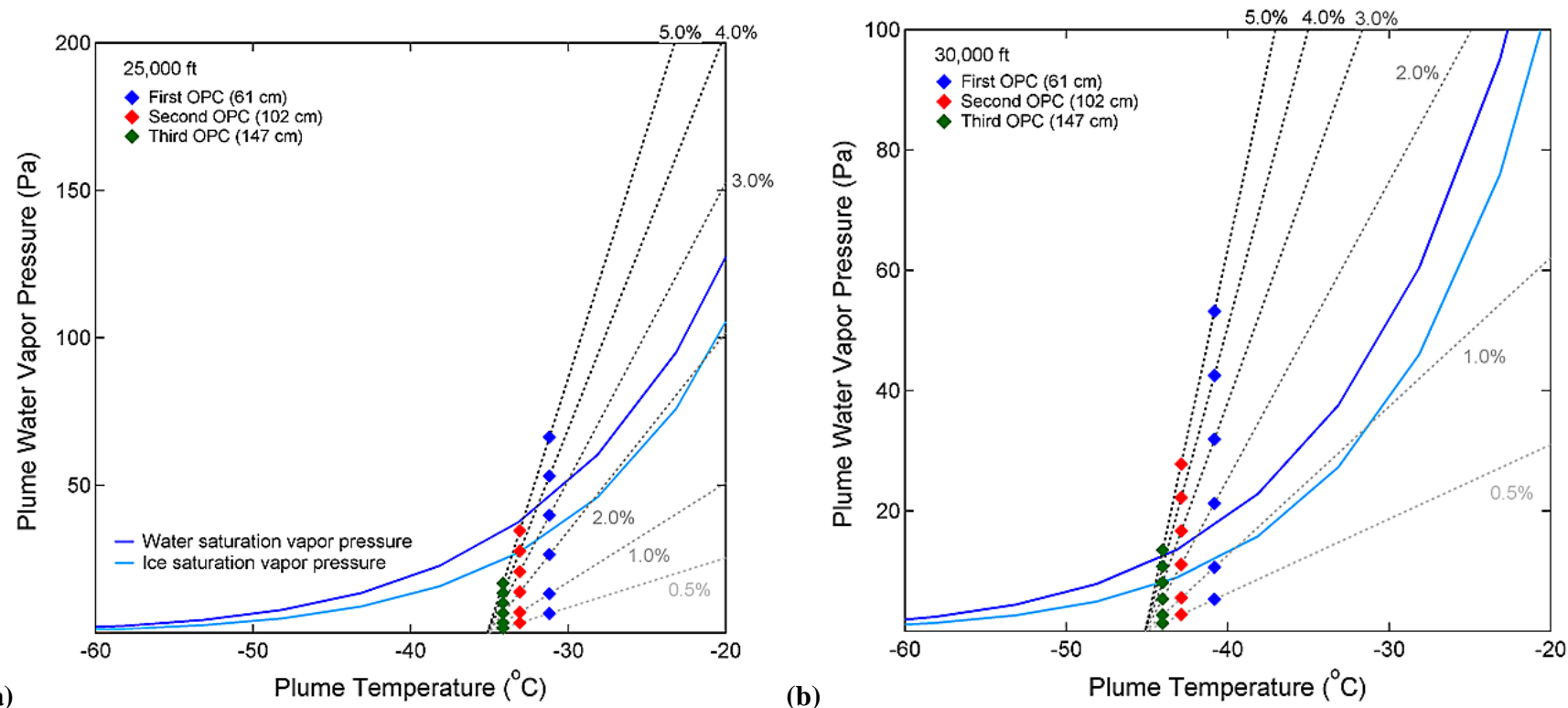

(a)

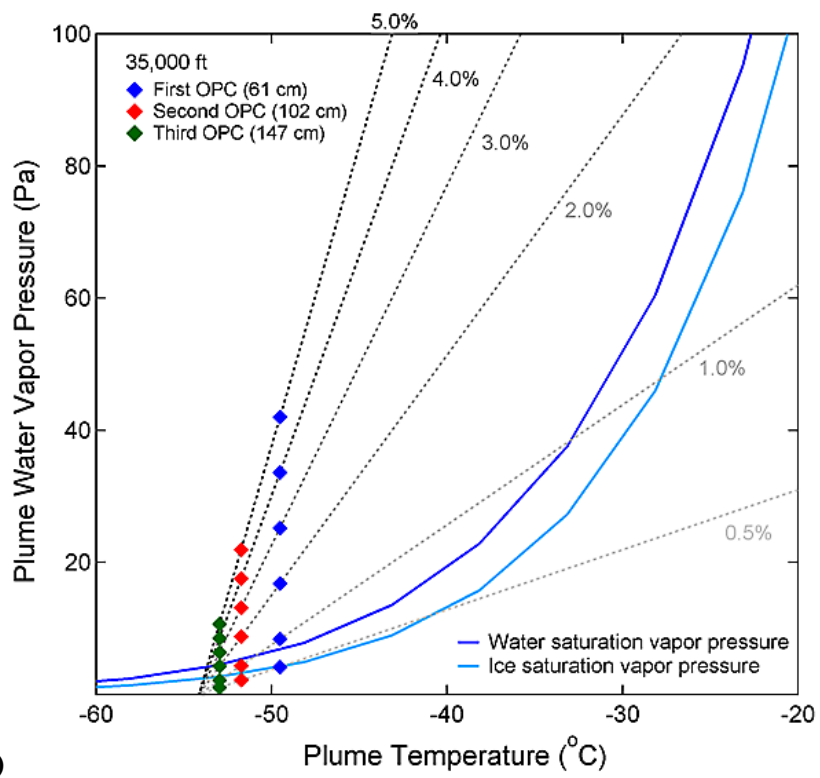

(b)

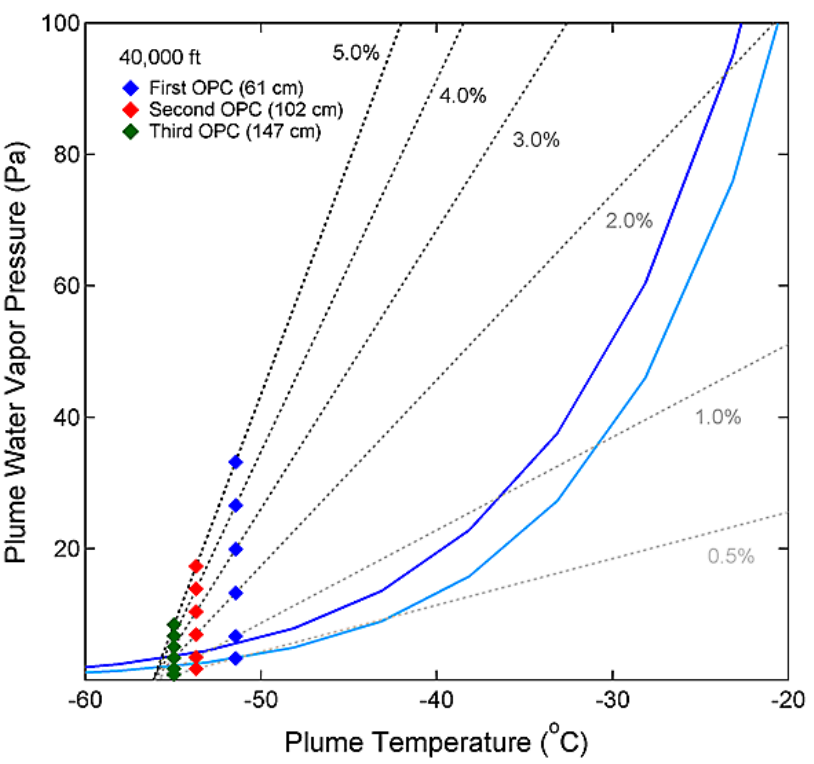

Fig. 2. Water and ice saturation vapor pressure curves, plume mixing lines for exhaust water levels between $0.5-5 \%$ in molar fraction, and plume temperature and water vapor pressure at the three sampling locations derived from the tracer measurements under (a) 25000, (b) 30 000, (c) 35 000, and (d) $40000 \mathrm{ft}$ standard day conditions in the PAL chamber.

In our model, homogeneous nucleation of new liquid particles is described by the kinetic quasi-unary nucleation theory developed by Yu $(2005,2006,2007)$. Coagulation of different liquid particles is described using Brownian coagulation kernels (Fuchs, 1989). Activation of hydrophobic soot surface and condensational growth of water vapor on soot are treated the same way as in Kärcher (1998) and our previous studies (Wong et al., 2008; Wong and Miake-Lye, 2010; Wong et al., 2011). Finally, the heterogeneous freezing rate of liquid water coatings on soot is described by the expression reported by Fornea et al. (2009).

\section{Results and discussions}

\subsection{Effect of exhaust water vapor content}

Our first set of experiments investigated the effect of exhaust water vapor content on the formation of contrail ice particles. In this set of experiments, the soot particles introduced by the miniCAST burner were kept constant at $2 \times 10^{5} \mathrm{~cm}^{-3}$ with $30 \mathrm{~nm}$ in diameter. The chamber background temperature and pressure were also kept constant at $35000 \mathrm{ft}$ standard day conditions as listed in Table 1 (i.e., $-54.2^{\circ} \mathrm{C}$ in temperature and $238 \mathrm{hPa}$ in pressure). Water vapor content 
Table 1. Standard day conditions examined in our PAL work and threshold temperature and exhaust water molar fraction for contrail formation associated with each condition. The threshold conditions were calculated using the Schmidt-Appleman criterion formulated in Schumann (1996).

\begin{tabular}{lrrrr}
\hline Cruising altitude $(\mathrm{ft})$ & 25000 & 30000 & 35000 & 40000 \\
\hline Ambient temperature $\left({ }^{\circ} \mathrm{C}\right)$ & -35.2 & -45.2 & -54.2 & -56.2 \\
Ambient pressure $(\mathrm{hPa})$ & 376.5 & 301.49 & 238.00 & 188.23 \\
Threshold temperature $\left({ }^{\circ} \mathrm{C}\right.$ ) when & & & & \\
exhaust water molar fraction is at $0.5 \%$ & -51.1 & -54.0 & -56.8 & -59.0 \\
exhaust water molar fraction is at $1.0 \%$ & -44.3 & -47.4 & -50.4 & -52.7 \\
exhaust water molar fraction is at $2.0 \%$ & -37.0 & -40.3 & -43.5 & -46.0 \\
exhaust water molar fraction is at 3.0\% & -32.4 & -35.9 & -39.2 & -41.9 \\
exhaust water molar fraction is at $4.0 \%$ & -29.0 & -32.6 & -36.1 & -38.8 \\
exhaust water molar fraction is at 5.0\% & -26.3 & -30.0 & -33.6 & -36.4 \\
Threshold exhaust water molar fraction & $2.35 \%$ & $1.25 \%$ & $0.67 \%$ & $0.69 \%$ \\
\hline
\end{tabular}

in the exhaust was varied between $0-5 \%$ in molar fraction. To reduce fluctuations in ice particle concentration measurements, each level of water vapor content was held constant for approximately $1 \mathrm{~min}$ before switching to the next level, as illustrated in Fig. 3. Our experimental results show that exhaust water vapor concentration has a dominant effect on ice particle formation. As shown in Fig. 3, particle extinction coefficients measured at $61 \mathrm{~cm}$ downstream of the nozzle increased with increasing exhaust water vapor content. OPC measurements, however, did not observe ice particles formed until a certain level of exhaust water content was reached (this level was about 3\% in molar fraction in Fig. 3). Above this level, increased ice particle concentration was measured by the OPC with increasing exhaust water vapor concentration, consistent with the extinction data. Since the SchmidtAppleman criterion suggests that the threshold exhaust water level is $0.67 \%$ in molar fraction (Table 1), lower than the level observed by the OPC, our measurement results imply that ice particles formed under exhaust water levels lower than $3 \%$ in molar fraction were too small to be detected by the OPC.

To further understand what can be learned from our measurement data, we performed detailed microphysical parcel simulations using the model described in Sect. 3. To simplify our simulations, only the dilution profiles describing average mixing behavior in the exhaust centerline were used. As a result, turbulent mixing in the chamber was not considered in calculating dilution history that was used in our microphysical simulations. Note that we did not introduce compounds that can activate hydrophobic soot surfaces in the experiments (such as sulfuric acid) but observed ice particle formation in the chamber. Filter samples of the soot particles generated from the miniCast were collected and analyzed with a Sunset Laboratory organic-to-elemental carbon (OC/EC) analyzer (Birch and Cary, 1996), and an OC/EC ratio of 2-5 was found. Because a volatile organic denuder was not used before the filter, this ratio can only be viewed as an upper limit for the amount of organic carbon. Previous studies

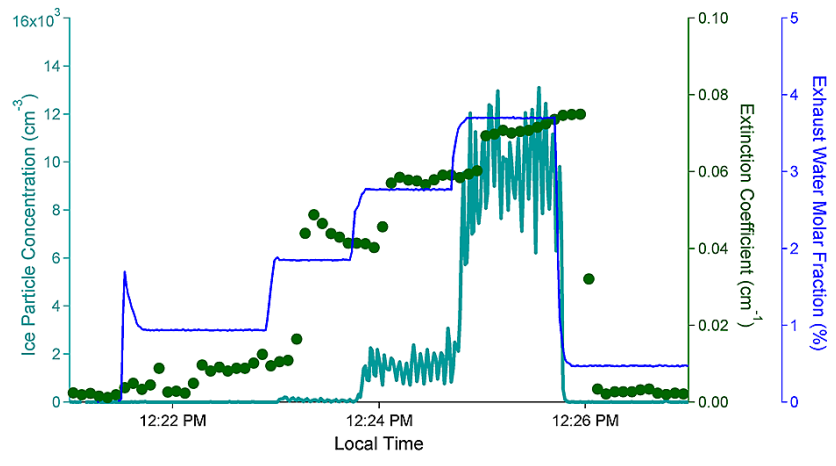

Fig. 3. Effect of water vapor level in the exhaust on ice particle formation: real-time measurement of OPC ice particle concentration (turquoise) and particle optical extinction coefficient (green) at $61 \mathrm{~cm}$ downstream of the exhaust nozzle when the exhaust water vapor level (blue) was varied between $0-4 \%$ in molar fraction in the exhaust. Note that each water level was held constant for approximately $1 \mathrm{~min}$ in order for the ice concentrations to stabilize.

have found OC/EC ratios of 1 when the larger version of the miniCAST was used to produce $30 \mathrm{~nm}$ soot particles from propane. The OC /EC analysis suggests that the soot surfaces were coated with organic carbon atoms, some of which may be oxygenated, hydrophilic carbon atoms. Consequently, we assumed in the model that $20 \%$ of the soot surface area is pre-activated. We did not observe significant sensitivity to this quantity in our model calculations as long as larger than $5 \%$ of the initial soot surface area was assumed to be activated. Future laboratory studies are planned to quantify and control the hydrophilic fraction of the soot surface.

Figure $4 \mathrm{a}$ shows a comparison between the predicted and measured ice particle concentration at $61 \mathrm{~cm}$ downstream of the exhaust nozzle. To be consistent with the known OPC instrument limitation, the model assumed that any particle smaller than $300 \mathrm{~nm}$ is not detectable. As the figure depicts, the model predicts a sharp onset of ice particle formation at an exhaust water level of about $0.5 \%$ in molar fraction. 
This is close to the prediction of $0.67 \%$ from the SchmidtAppleman criterion described earlier. The onset of ice particle formation measured by the OPC, however, is less steep and at a higher exhaust water level. Figure $4 \mathrm{a}$ also compares the predicted and measured fraction of the ice particles that are larger than $1 \mu \mathrm{m}$ (termed as super-micron fraction) as a function of exhaust water level. Similar to what is shown for ice particle concentration, a sharper onset of ice particle super-micron fraction at a lower exhaust water vapor concentration is predicted by the model compared to the experiments. The model also predicts greater ice particle supermicron fraction, which reaches $100 \%$ at exhaust water levels of more than $0.6 \%$ in molar fraction compared to at most about $20 \%$ measured experimentally. The discrepancy between the model and the OPC measurements is due to the overprediction of ice particle size in the model (about a factor of two). This overprediction is likely from two sources. First, the model only considered a smooth dilution history in the chamber centerline and did not consider any turbulent mixing effects that could alter the history of water vapor concentration in the radial direction of the chamber. Since turbulent mixing introduces more deviation in the dilution history of water vapor, some liquid water coated soot under threshold conditions might not freeze to form ice particles. Indeed, our model predicted very narrow particle size distributions for the PAL experiments, but the OPC measured ice particle super-micron fraction suggests that wider ice particle size distributions existed in the chamber. Second, the model did not consider the potential ice particle scatter and loss in the sampling process. Although particle evaporation was minimized by introducing a high flow rate in the sampling lines, particle scatter and loss may not be completely avoided. Since OPCs have a cutoff of particle size at $300 \mathrm{~nm}$, any particle scatter during the sampling process will result in reduced particle size, causing more ice particles undetectable by the OPC and reducing the ice particle concentration measured experimentally. The possible particle scatter and loss in the sampling process may also contribute to the reduction of the ice particle super-micron fraction measured by the OPCs.

Although our model showed quantitative disagreement with the OPC measurements, our model is able to capture the trends of the extinction data well, as depicted in Fig. 4b. Both measured extinction coefficients and model predicted ice particle concentration $(N)$ multiplied by particle diameter squared $\left(d^{2}\right)$ increased with exhaust water vapor levels with the same relative magnitude, consistent with the particle extinction theory described in Eq. (3). Since particle loss and scatter was not a factor in the extinction measurements, this good agreement between the model and the measurements further suggests that particle scatter and loss in the sampling lines was a primary reason responsible for the disagreement between the model and the OPC measurements.

A similar set of experiments varying exhaust water vapor contents were also performed without introducing any soot particles. In that set of experiments, we did not observe any
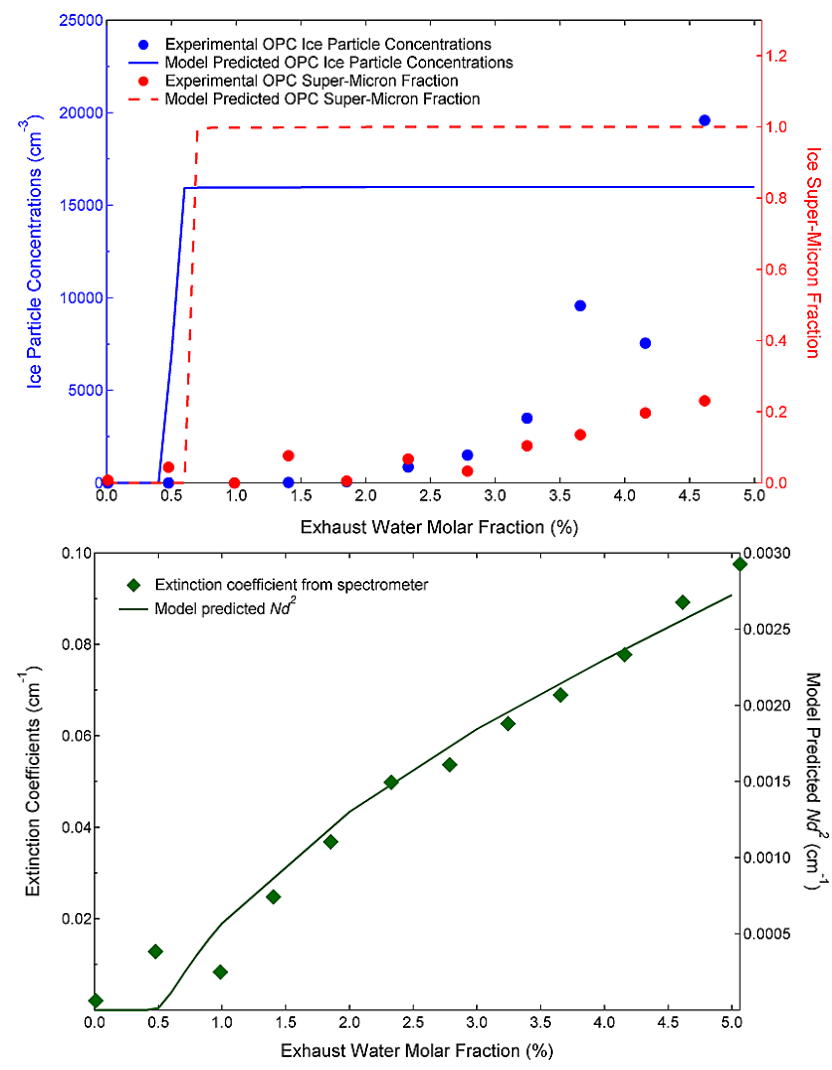

Fig. 4. Comparison of experimental and modeling results as a function of exhaust water molar fraction at $61 \mathrm{~cm}$ downstream of the exhaust nozzle: (a) model predicted and OPC measured ice particle concentration and ice particle super-micron fraction; (b) measured particle optical extinction and predicted ice particle concentration $(N)$ multiplied by particle diameter squared $\left(d^{2}\right)$.

evidence of ice particle formation even at an exhaust water vapor level of $5 \%$ in molar fraction. This suggests that ice particle formation from homogeneous nucleation followed by homogeneous freezing of liquid water is unfavorable under the conditions studied in this work. Note that a background particle concentration between 10 and $400 \mathrm{~cm}^{-3}$ was measured using a condensation particle counter at the top of the chamber, regardless the amount of water injection into the chamber. These background particles may serve as ice nuclei, but the amount of ice particles measured from the OPCs was negligible and no visual contrail was observed in the video snapshots. Also note that this observation may change if sulfuric acid is present in the exhaust, as suggested by the recent modeling study by Kärcher and Yu (2009).

\subsection{Effect of soot emissions}

The second key parameter investigated in our laboratory and modeling studies is the effect of soot particles emitted into the chamber. Several sets of experiments were performed with constant chamber conditions and exhaust water level 
but with variable soot particle concentrations ranging from $10^{2}-10^{7} \mathrm{~cm}^{-3}$. Figure 5 illustrates one of these sets of experiments, where exhaust water level was set at $2 \%$ in molar fraction and the chamber was set at $40000 \mathrm{ft}$ standard day conditions $\left(-56.2^{\circ} \mathrm{C}\right.$ and $\left.188.23 \mathrm{hPa}\right)$. Note that the soot particles introduced in this experiment set were kept as close to the same size as possible, and soot particle concentration was increased from about $10^{3}$ to $10^{7} \mathrm{~cm}^{-3}$ and back to $10^{3} \mathrm{~cm}^{-3}$ to study experimental reproducibility. A video camera focused on the intersection of the xenon light beam and the exhaust plume was employed for visual confirmation of particle formation. As shown in the figure, maximum ice number concentration measured by the OPC at $61 \mathrm{~cm}$ downstream of the nozzle was observed at a soot concentration of about $10^{6} \mathrm{~cm}^{-3}$. When soot particle concentration was introduced above this level, the measured ice particle concentration decreased. However, particles were still visible in the video snap shots when OPC measured this reduced ice concentration. This is likely due to the size limitation of the OPC, by which any liquid or ice particles smaller than $300 \mathrm{~nm}$ in diameter cannot be detected. The decrease in ice particle super-micron fraction with increasing number of soot particles injected into the chamber (color coded in the ice concentration curve in Fig. 5) further supports this statement. Our OPC results suggest that smaller ice particles were formed when higher concentration of soot particles was introduced, implying that competition for water vapor condensation among soot particles existed. This is also consistent with findings from our previous modeling study (Wong and Miake-Lye, 2010).

We again performed model simulations to assist experimental data analysis and interpretation. Figure $6 a$ shows a comparison between the predicted and measured ice particle concentration under two different exhaust water levels at $30,000 \mathrm{ft}$ standard day conditions $\left(-45.2^{\circ} \mathrm{C}\right.$ and $301.49 \mathrm{hPa}$ ). As shown in the figure, model predicted ice particle concentrations at initial soot concentrations lower than about $1 \times 10^{5} \mathrm{~cm}^{-3}$ agree very well with experimental data when exhaust water level is at $2-3 \%$ in molar fraction. However, at soot concentrations higher than $1 \times 10^{5} \mathrm{~cm}^{-3}$, the model overpredicts ice particle concentrations by as large as about two orders of magnitude. This is because the model overpredicted ice particle size (by about a factor of two, similar to what is mentioned in the previous section), and consequently the number of ice particles that are larger than the OPC cutoff at $300 \mathrm{~nm}$ was overpredicted. The size discrepancy between the model and experiments may be due to particle scatter and loss during the sampling process not accounted for in the model, as discussed previously. At $0.5 \%$ molar fraction of exhaust water level, the model predicted no ice particle formation, the same trend observed experimentally for $0-1 \%$ exhaust water molar fraction. This is because at $30000 \mathrm{ft}$ standard day conditions, at least $1.25 \%$ molar fraction of exhaust water level is needed to induce contrail formation, as listed in Table 1. This set of results suggest that

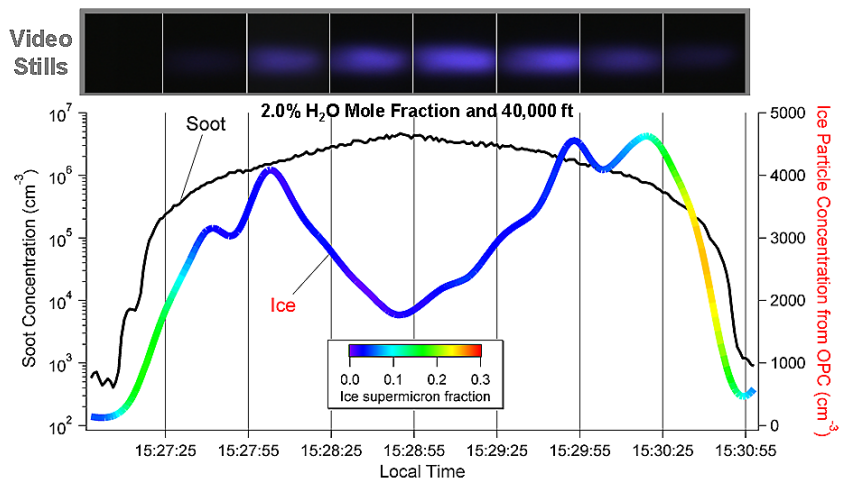

Fig. 5. The OPC measured ice particle concentration and ice supermicron fraction along with video snap shots during a soot concentration scan.

our PAL measurements can reproduce what is predicted from the Schmidt-Appleman criterion very well and can be used as a well-controlled and cost-effective way to study contrail ice formation.

Figure $6 \mathrm{~b}$ compares model predicted and measured ice particle super-micron fraction at $61 \mathrm{~cm}$ downstream of the nozzle. The figure shows that the model is able to capture the fall-off of the super-micron fraction when exhaust water level is at $2-3 \%$ in molar fraction. The predicted ice particle super-micron fraction from the model, however, is about a factor of two larger than what was measured experimentally. Again, this is likely due to the effect of particle scatter and loss in the sampling lines and the lack of turbulent mixing treatment in the model. Since no significant amount of ice particles was measured or predicted at an exhaust water level of $0-1 \%$ in molar fraction (Fig. 6a), a large uncertainty in the experimental super-micron fraction exists at this exhaust water level and its comparison to model predicted zero super-micron fraction is not meaningful.

The model predicted ice particle concentration $(N)$ multiplied by ice particle diameter squared $\left(d^{2}\right)$ was again compared to the measured particle extinction data for this set of experiments, as illustrated in Fig. 6c. Both extinction coefficients and model predicted $N d^{2}$ values increased with increasing soot concentration introduced into the chamber. The linearity of the increase before a soot concentration of $1 \times 10^{5} \mathrm{~cm}^{-3}$ suggests that soot particles served as ice nuclei, and each soot injected was responsible for each ice particle formed. The nonlinear region at high soot concentrations show particle size effect, confirming that smaller ice particles were formed when more soot particles were injected due to competition for water vapor. Again, our model agreed with the extinction data trends very well, suggesting that particle scatter and loss in the sampling lines contributed to the disagreements between the model and the OPC measurements. 


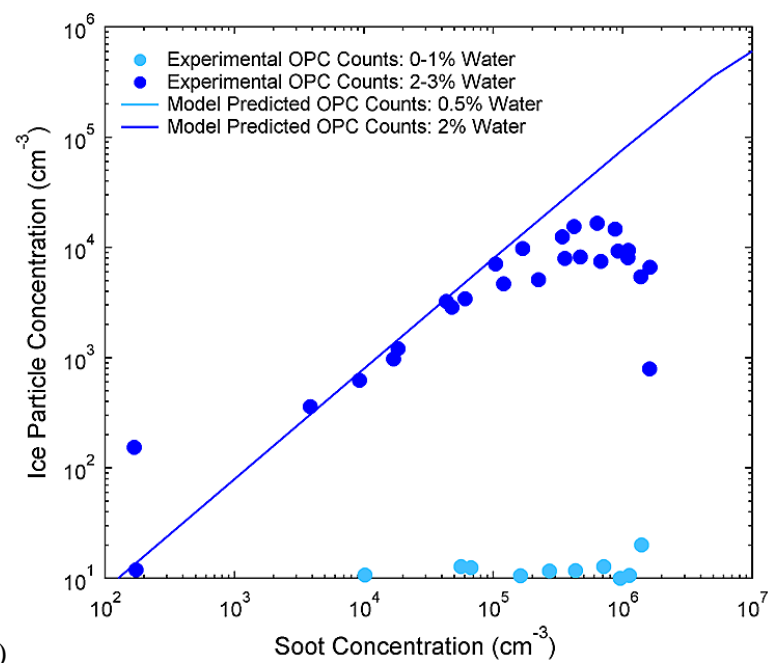

(a)

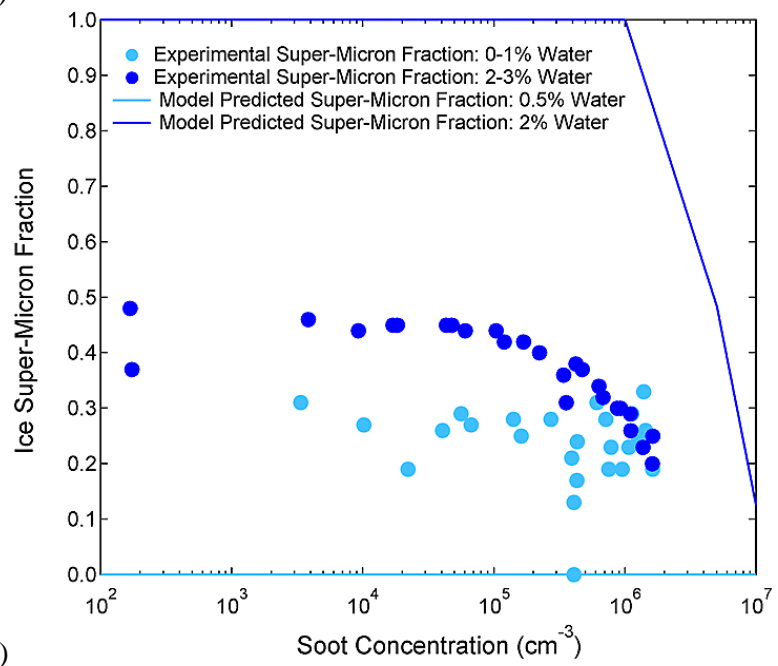

(b)

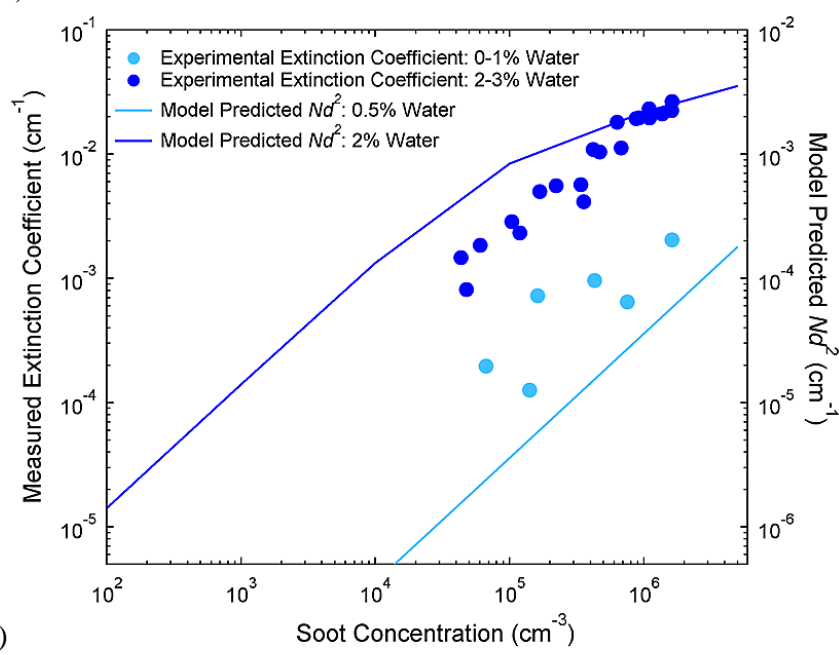

Fig. 6. Comparison of (a) model predicted and measured ice particle concentration from the OPCs (note that at $0.5 \%$ molar fraction of exhaust water level, the model predicted no ice particle formation), (b) model predicted and measured ice particle super-micron fraction, and (c) measured ice particle extinction coefficients and model predicted ice particle concentration $(N)$ multiplied by particle diameter squared $\left(d^{2}\right)$. The measurements were performed at $61 \mathrm{~cm}$ downstream of the nozzle under $30000 \mathrm{ft}$ standard day conditions.

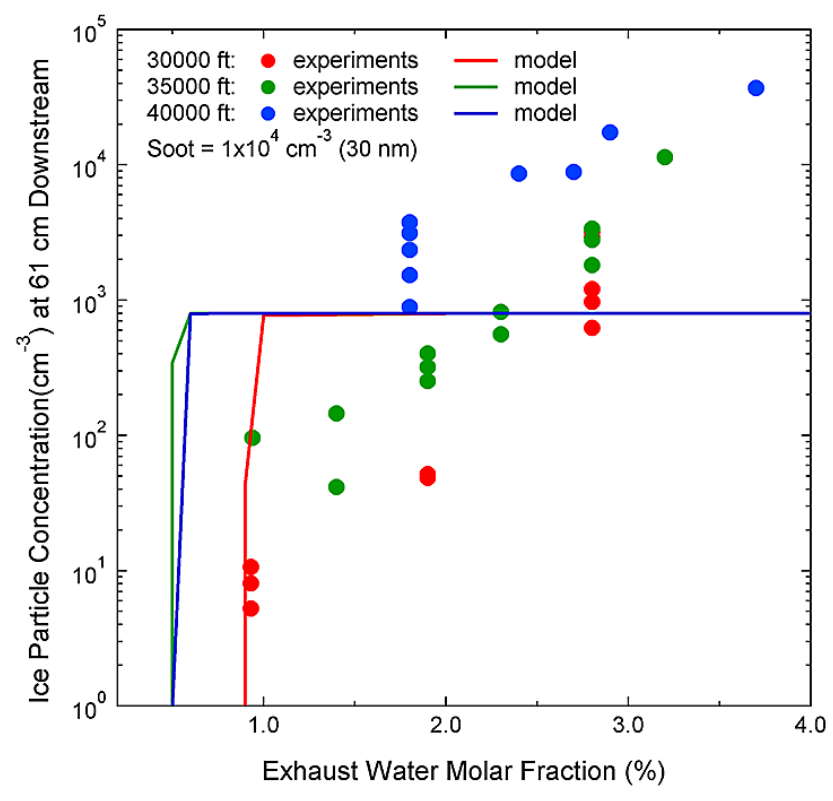

Fig. 7. Comparison of experimental and modeling results on OPC measured ice particle concentration at $61 \mathrm{~cm}$ downstream of the nozzle under three different chamber conditions.

\subsection{Effect of chamber conditions}

Figure 7 shows model prediction on ice particle concentration at $61 \mathrm{~cm}$ downstream of the nozzle under three different chamber conditions. As depicted in the figure, our model predicts that the onset of ice particle formation takes place at lower exhaust water levels under higher altitude conditions. The model also predicts a sharp onset of ice particle formation with respect to exhaust water level for each chamber condition. This onset of exhaust water level was about $0.5-0.6 \%$ in molar fraction under 40000 and $35000 \mathrm{ft}$ standard day conditions and about $1 \%$ in molar fraction under $30000 \mathrm{ft}$ standard day conditions. This is very close to the predictions from the Schmidt-Appleman criterion, as listed in Table $1(0.69,0.67$, and $1.25 \%$ for the three conditions). Figure 7 also shows ice particle concentrations measured by the OPC at $61 \mathrm{~cm}$ downstream of the nozzle under different chamber conditions. Unlike the modeling results, higher concentration of ice particles were measured under higher altitude conditions (i.e., lower chamber temperature and pressure). Again, this discrepancy is likely due to the effect of particle loss and scatter during the sampling process and the lack of treatment of turbulent mixing in the model. However, both the model and the experiments show that higher cruising altitudes favor the formation of contrail ice particles. 


\section{Conclusions}

In this paper, we present results from our recent laboratory and modeling investigation of the effects of water and soot emissions and ambient conditions on the near-field formation of contrail ice particles. The Particle Aerosol Laboratory (PAL) at the NASA Glenn Research Center and the Aerodyne microphysical parcel model for contrail ice particle formation were employed. Our studies show that exhaust water level has a significant effect on contrail ice particle formation. An onset exhaust water level of ice particle formation existed when soot was present. When no soot or sulfuric acid was introduced, ice particle formation from homogeneous nucleation followed by homogeneous freezing of liquid water was found to be unfavorable. Soot particles were found to compete for water vapor condensation, and higher soot concentration emitted into the chamber resulted in smaller ice particles. Chamber conditions corresponding to higher altitude cruising conditions were found to favor ice particle formation as expected. The microphysical model captures the trends of extinction data well, but discrepancies between the model and the OPC measurements exist. These discrepancies are likely due to particle loss and scatter during the experimental sampling process and the lack of treatment of turbulent mixing in the model. Our work demonstrates that the NASA Glenn PAL facility is able to reproduce contrail ice particle formation under inflight measurement conditions. Parametric understanding obtained from our combined modeling and experimental approach can provide better estimates of ice particle properties, such as number density and size, used in large-scale models predicting contrail radiative forcing and contrail climate impact. Potential extension of our work includes studying the effects of soot surface coverage, soot surface hydrophilicity, and sulfuric acid concentration on contrail ice particle formation using a combination of the PAL and the microphysical model.

Acknowledgements. The authors are grateful for financial support from the Federal Aviation Agency (FAA) Aviation Climate Change Research Initiative (ACCRI) via the Department of Transportation Volpe Center (Contract No. DTRT57-10-C-10014) and the NASA Subsonic Fixed-Wing, Clean Energy and Emissions Project.

Edited by: A. Nenes

\section{References}

Appleman, H.: The formation of exhaust condensation trails by jet aircraft, B. Am. Meteor. Soc., 34, 14-20, 1953.

Beer, J. M. and Chigier, N. A.: Combustion Aerodynamics, Halsted Press Division, John Wiley and Sons, Inc., New York, NY, 1972.

Birch, M. E. and Cary, R. A.: Elemental carbon-based method for monitoring occupational exposures to particulate diesel exhaust, Aerosol Sci. Technol., 25, 221-241, 1996.
Busen, R. and Schumann, U.: Visible contrail formation from fuels with different sulfur contents, Geophys. Res. Lett., 22, 13571360, 1995.

Brasseur, G. P. and Gupta, M.: Impact of aviation on climate, B. Am. Meteor. Soc., 91, 461-463, 2010.

Brown, R. C., Anderson, M. R., Miake-Lye, R. C., Kolb, C. E., Sorokin, A. A., and Buriko, Y. Y.: Aircraft exhaust sulfur emissions, Geophys. Res. Lett., 23, 3603-3606, 1996.

Fornea, A. P., Brooks, S. D., Dooley, J. B., and Saha, A.: Heterogeneous freezing of ice on atmospheric aerosols, J. Geophys. Res., 114, D13201, doi:10.1029/2009JD011958, 2009.

Fuchs, N. A.: The mechanics of aerosols, 2nd Edn., Dover Publications, Inc., New York, NY, 1989.

Heymsfield, A., Baumgardner, D., DeMott, P., Forster, P., Gierens, K., and Kärcher, B.: Contrail microphysics, B. Am. Meteor. Soc., 91, 465-472, 2010.

Jensen, E., Toon, O., Kinne, S., Sachse, G., Anderson, B., Chan, K., Twohy, C., Gandrud, B., Heymsfield, A., and Miake-Lye R.: Environmental conditions required for contrail formation and persistence, J. Geophys. Res., 103, 3929-3936, 1998.

Kärcher, B.: Physicochemistry of aircraft-generated liquid aerosols, soot, and ice particles 1. Model description, J. Geophys. Res., 103, 17111-17128, 1998.

Kärcher, B. and Yu, F.: Role of aircraft soot emissions in contrail formation, Geophys. Res. Lett., 36, L01804, doi:10.1029/2008GL036649, 2009.

Kärcher, B., Peter, T., Biermann, U. M., and Schumann, U.: The initial composition of jet condensation trails, J. Atmos. Sci., 53, 3066-3083, 1996.

Kärcher, B., Rusen, R., Petzold, A., Schroder, F. P., and Schumann, U.: Physicochemistry of aircraft-generated liquid aerosols, soot, and ice particles 2 . Comparison with observations and sensitivity studies, J. Geophys. Res., 103, 17129-17147, 1998.

Lee, D. S., Fahey, D. W., Forster, P. M., Newton, P. J., Wit, R. C. N., Lim, L. L., Owen, B., and Sausen, R.: Aviation and global climate change in the 21 st century, Atmos. Environ., 43, 3520 3537, 2009.

Nickels, T. B. and Perry, A. E.: An experimental and theoretical study of the turbulent coflowing jet, J. Fluid Mech., 309, 157182, 1996.

Penner, J. E., Lister, D. H., Griggs, D. J., Dokken, D. J., and McFarland, M. (Eds.): Aviation and the global atmosphere, Cambridge University Press, Cambridge, UK, 1999.

Petzold, A., Schloesser, H., Sheridan, P. J., Arnott, W. P., Ogren, J. A., and Virkkula, A.: Evaluation of multiangle absorption photometry for measuring aerosol light absorption, Aerosol Sci. Technol., 39, 40-51, 2005.

Schmidt, E.: Die entstehung von eisnebel aus den auspuffgasen von flugmotoren, Schriften der Deutschen Akademie der Luftfahrtforschung, 44, 1-15, 1941.

Schumann, U.: On conditions for contrail formation from aircraft exhausts, Meteorol. Zeitschrift, 5, 4-23, 1996.

Schumann, U.: Formation, properties and climate effects of contrails, C. R. Phys., 6, 549-565, 2005.

Schumann, U., Ström, J., Busen, R., Baumann, R., Gierens, K., Krautstrunk, M., Schröder, F. P., and Stingl, J.: In situ observations of particles in jet aircraft exhausts and contrails for different sulfur-containing fuels, J. Geophys. Res., 101, 6853-6869, 1996. 
Schumann, U., Arnold, F., Busen, R., Curtius, J., Kärcher, B., Kiendler, A., Petzold, A., Schlager, H., Schröder, F., and Wohlfrom, K.-H.: Influence of fuel sulfur on the composition of aircraft exhaust plumes: The experiments SULFUR 1-7, J. Geophys. Res., 107, 4247, doi:10.1029/2001JD000813, 2002.

Tacina, K. M. and Heath, C. M.: Evolution of combustion-generated particles at tropospheric conditions, in: Proceedings of ASME Turbo Expo 2010: Power for Land, Sea and Air (GT2010), Glasgow, UK, 14-18 June, 2010, Vol. 2: Combustion, Fuels and Emissions, Parts A and B, ISBN 978-0-7918-4397-0, Paper No. GT2010-23689, 1289-1299, 2010.

Timko, M. T., Onasch, T. B., Northway, M. J., Jayne, J. T., Canagaratna, M., Herndon, S. C., Wood, E. C., Miake-Lye R. C., and Knighton, W. B.: Gas turbine engine emissions part 2. Chemical properties of particulate matter, ASME J. Eng. Gas Turbines Power, 132, 061505, doi:10.1115/1.4000132, 2010.

Wang, J. Storey, J., Domingo, N., Huff, S., Thomas, J., and West, B.: Studies of diesel engine particle emissions during transient operations using an engine exhaust particle sizer, Aerosol Sci. Technol., 40, 1002-1015, 2006.
Wong, H.-W. and Miake-Lye, R. C.: Parametric studies of contrail ice particle formation in jet regime using microphysical parcel modeling, Atmos. Chem. Phys., 10, 3261-3272, 2010, http://www.atmos-chem-phys.net/10/3261/2010/.

Wong, H.-W., Yelvington, P. E., Timko, M. T., Onasch, T. B., Miake-Lye, R. C., Zhang, J., and Waitz, I. A.: Microphysical modeling of ground-level aircraft-emitted aerosol formation: Roles of sulfur-containing species, J. Propul. Power, 24, 590 602, 2008.

Wong, H.-W., Yu, Z., Timko, M. T., Herndon, S. C., Blanco, E. d. 1. R., and Miake-Lye, R. C.: Design parameters for an aircraft engine exit plane particle sampling system, ASME J. Eng. Gas Turbines Power, 133, 021501, doi:10.1115/1.4001979, 2011.

Yu, F.: Quasi-unary homogeneous nucleation of $\mathrm{H}_{2} \mathrm{SO}_{4}-\mathrm{H}_{2} \mathrm{O}$, J. Chem. Phys., 122, 074501, doi:10.1063/1.1850472, 2005.

$\mathrm{Yu}, \mathrm{F}$.: Binary $\mathrm{H}_{2} \mathrm{SO}_{4}-\mathrm{H}_{2} \mathrm{O}$ homogeneous nucleation based on kinetic quasi-unary nucleation model: Look-up tables, J. Geophys. Res., 111, D04201, doi:10.1029/2005JD006358, 2006.

$\mathrm{Yu}, \mathrm{F}$.: Improved quasi-unary nucleation model for binary $\mathrm{H}_{2} \mathrm{SO}_{4}$ $\mathrm{H}_{2} \mathrm{O}$ homogeneous nucleation, J. Chem. Phys., 127, 054301, doi:10.1063/1.2752171, 2007. 